Journal of the Operations Research

Society of Japan

Vol. 30, No. 3, September 1987

\title{
ON THE SOJOURN TIME DISTRIBUTION IN CYCLIC QUEUEING SYSTEMS WITH A LiPS STATION
}

\author{
Takeshi Kawashima \\ The National Defense Academy
}

(Received April 10, 1986; Final March 10, 1987)

\begin{abstract}
We consider a cyclic queueing network with two service stations, nodes 1 and 2 . Node 1 has $s$ servers and the FCFS discipline. Node 2 processes jobs under the $m$-limited processor sharing ( $m$-LiPS) discipline, which is a generalization of the processor sharing (PS) discipline. We consider the joint distribution of successive sojourn times of a job at the two nodes, and propose a simple method to describe the Laplace-Stieltjes transform (LST) and the moments of these variables by their conditional marginal distributions. Further, we deduce linear equations giving the moments and the LST for an $m$-LiPS node. For some cases, the correlation coefficients and the coefficients of variation of the total sojourn times are calculated numerically.
\end{abstract}

\section{Introduction}

The processor sharing discipline (PS) is one of the interesting disci= plines in computer engineering. In a service station with this discipline, the server's capacity is shared equally by all jobs present in the station. It may be impossible, however, to be shared by too many jobs because of the limitation of memory size and so forth. Yamazaki and Sakasegawa [16] proposed the $m$-limited processor sharing ( $m$-LiPS) discipline, where $m$ is a positive integer. In an m-LiPS station, the server's capacity is shared equally by at most $m$ jobs present in the station, and the rest of the jobs, if any, have to wait for service in the queue in the arrival order. Clearly, the FCFS discipline at a single server station is described as the 1-LiPS discipline. If $m$ is not less than the attainable maximum queue length, the m-LiPS discipline coincides with the PS discipline. In a computer system with $m$ pseudo processors called "init" or "initiator", its job processing mechanism is modeled às an m-liPs station (cf. Ishiguro [7]). 
In this paper, we consider a cyclic queueing network with two service stations, nodes 1 and 2 (see Fig. 1). Node 1 has $s$ servers and the FCFS discipline. Node 2 processes jobs under the m-LiPS discipline. The total number of jobs in the system is $N$. Service requirements of each job at nodes 1 and 2 are independent exponentially distributed random variables with rate $\mu_{1}$ and $\mu_{2}$, respectively. Our purpose is to analyze the joint distribution of successive sojourn times at nodes 1 and 2 experienced by one job. Generally, computer users are interested in the characteristics of sojourn times or their own response times. It is well known that the equilibrium state probabilities for this system are expressed as product form solutions. The equilibrium state probabilities, however, do not give sufficient information for the sojourn times by themselves.

Here, we show that the joint distribution can be described by combining the marginal distributions, invoking the reversible Markov property. Further, we derive linear equations giving the Laplace-Stieltjes transform (LST) and the moments of the sojourn time at the m-LiPS node. Numerical results can be obtained easily from our result. For some cases, the coefficient correlations and the coefficients of variation of the total sojourn times are calculated numerically.

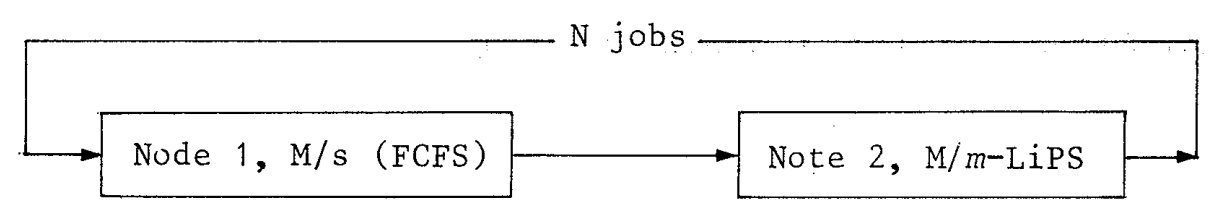

Fig. 1. Cyclic Queueing System

\section{Preliminary and Related Results}

Let $q_{i}(t) \quad(-\infty<t<\infty)$ by the number of jobs present at node $i(i=1,2)$ at time $t$. Since $q_{1}(t)+q_{2}(t)=N$. holds always, the system's behaviour can be described by $q_{2}(t)$, which is used mainly. We denote $q_{2}(t)$ by $q(t)$ simpiy. According to the description of our system, $q(t)$ is an ergodic Markov process. Let $P$ be a probability measure under which $q(t)$ is in equilibrium. Then, we have the following for any $t \varepsilon(-\infty, \infty)$,

$$
P(q(t)=q)=G(N)^{-1} \mu_{2}^{-q} \Pi_{j=1}^{N-q}\left(\min (j, s) \mu_{1}\right)^{-1} \quad(q=0,1, \ldots, N),
$$

where $G(N)$ is a normalizing constant. We denote the right hand side of (2.1) by $f_{N}(q)$ for converience. 
With respect to $P$, two sequences of arrival times of jobs at nodes 1 and 2 are stationary point processes, from each of which we can define Palm provability measures $P_{1}$ and $P_{2}$, respectively (cf. Franken, et al., p.23 [6]). $P_{1}\left(P_{2}\right)$ is a measure which is strictly stationary for the sequence of arrival times at node 1 (node 2). $P_{1}$ can be also considered as a conditionally probability measure of $P$ under the condition that a job arrives at node 1 at time $t=0$, and $P_{2}$ be that under the condition that a job arrives at node 2 at $t=0$. We tag the job arriving at node 1 at $t=0$ under $P_{1}$ and the job arriving at node 2 under $P_{2}$, respectively. Let $W_{1}, W_{2}$ be consecutive sojourn times of the tagged jobs at node 1 and 2. Then, we have the following (cf. Kawashima [9]), which is proved from the ergodicity of $q(t)$.

$$
P_{1}\left(w_{1} \leqq x, w_{2} \leqq y\right)=P_{2}\left(w_{1} \leqq x, W_{2} \leqq y\right) .
$$

Let us consider the state of the other $N-1$ jobs at $t=0$. It is known that, with respect to both $P_{1}$ and $P_{2}$, the state distribution is identical to the equilibrium distribution of the system with $N=1$ jobs circulating (cf. Kawashima [8] or Lavenberg and Reiser [11]). We have

$$
P_{1}(q(0+)=q)=P_{2}(q(0+)=q+1)=f_{N-1}(q) \quad(q=0,1, \ldots, N-1) .
$$

In the following section, we deduce an expression of the joint distribution of $W_{1}$ and $W_{2}$ with respect to $P_{2}$, which holds true with respect to $P_{1}$.

For a system where nodes 1 and 2 are single-server nodes with the FCFS discipline, Chow [4] obtained the joint distribution of $W_{1}$ and $W_{2}$ with respect to $P_{1}$, which has so called a product form. Boxma and Donk [1] also obtained it with respect to $P_{2}$. For a system with many-server nodes, a similar expression is obtained by Kawashima and Torigoe [10]. Further, Schassberger and Daduna [15] considered a cyclic closed system consisting of a series of singleserver nodes, a series of infinite-server nodes and two many-servers nodes. The two series are connected by the two many-servers nodes at each ends. They showed that the joint distribution of the successive sojourn times has a product form, considering the LST's. Their result covers Schassberger and Daduna [14], Boxma and Donk [1]. For systems with PS or m-LiPS nodes, there has been no result concerning the joint distribution of the sojourn times, in our knowledge. However, some results for the marginal sojourn time distribution in a closed system are known. Mitra [12] considered a system where node 1 has infinite servers and node 2 has the PS discipline. He obtained the linear differential equations giving the distribution of the sojourn time at node 2 , and some numerical results. He also showed that the eigenvalues of the coefficient matrix are all real and nonpositive. Coffman, et. al. [5] obtained 
the LST and the some moments of the sojourn time in a PS node with a Poisson arrival process.

\section{Time Reversible Process}

A stationary Markov process $X(t)(-\infty<t<\infty)$ is said to be time reversible if its time reversed process $x(-t)$ is stochastically identical to $x(t)$. An equivalent condition to be reversible for $x(t)$ is as follows:

$$
P(s) R\left(s, s^{\prime}\right)=P\left(s^{\prime}\right) R\left(s^{\prime}, s\right) \text { for al1 s, } s^{\prime} \varepsilon S \text {, }
$$

where $S, P(s)$ and $R\left(s, s^{\prime}\right)$ are the state space, the equilibrium distribution and the transition rate of $X(t)$, respectively (cf. Reich [13]). For the process $q(t)$, we have

$$
R\left(q, q^{\prime}\right)=\left\{\begin{array}{cl}
\min (N-q, s) \mu_{1} & \text { if } q^{\prime}=q+1, q \geqq 0, \\
\mu_{2} & \text { if } q^{\prime}=q-1, q \geqq 1, \\
0 & \text { otherwise. }
\end{array}\right.
$$

From these and (2.1), we can easily verify that (3.1) holds. Thus, we have

Lemma 1. $g(t)$ is a time reversible Markov process.

Note that $q_{1}(t)$ is also a time reversible process. The following lemma is essential to deduce the joint distribution of $W_{1}$ and $W_{2}$. The proof is given in Appendix 1. The lemma means that the sojourn time of a job leaving $q$ jobs at node 1 is stochastically equal to that of a job finding $q$ jobs at its arrival instant.

Lemma 2. $p_{2}\left(w_{1} \leqq x \mid q_{1}(0+)=q\right)=P_{1}\left(w_{1} \leqq x \mid q_{1}(0+)=q+1\right)$.

\section{Joint Distribution of Sojourn Times}

We consider the joint distribution of $W_{1}$ and $W_{2}$ with respect to $P_{2}$. Since $W_{1}$ depends only on $q(-t)(t \geqq 0)$ and $W_{2}$ on $q(t)(t \geqq 0)$, they are conditionally independent under the condition that $q(0+)=q+1(q=0,1, \ldots, N-1)$. From $(2.3)$, we have

$$
\begin{aligned}
E_{2}\left(\exp \left(-z_{1} W_{1}-z_{2} W_{2}\right)\right) \\
\quad=\sum_{q=0}^{N-1} f_{N-1}(q) E_{2}\left(\exp \left(-z_{1} W_{1}-z_{2} W_{2}\right) \mid q(0+)=q+1\right) \\
\quad=\sum_{q=0}^{N-1} f_{N-1}(q) E_{2}\left(\exp \left(-z_{1} W_{1}\right) \mid q(0+)=q+1\right) E_{2}\left(\exp \left(-z_{2} W_{2}\right) \mid q(0+)=q+1\right),
\end{aligned}
$$


where $E_{i}$ is the expectation with respect to $P_{i}(i=1,2)$. Invoking Lemma 2 , we have the next.

Theorem.

$$
\begin{aligned}
& E_{2}\left(\exp \left(-z_{1} W_{1}-z_{2} W_{2}\right)\right) \\
& \quad=\sum_{q=0}^{N-1} f_{N-1}(q) E_{1}\left(\exp \left(-z_{1} W_{1}\right) \mid q_{1}(0-)=N-q-1\right) E_{2}\left(\exp \left(-z_{2} W_{2}\right) \mid q(0+)=q+1\right) .
\end{aligned}
$$

Now, observing that node 1 is FCFS, we have

$$
E_{1}\left(\exp \left(-z_{1} W_{1}\right) \mid q_{1}(0-)=N-q-1\right)
$$

$(4.1)$

$$
=\left(\frac{s \mu_{1}}{z_{1}+s \mu_{1}}\right)^{\max (N-q-s, 0)} \cdot \frac{\mu_{1}}{z_{1}+\mu_{1}} .
$$

In order to determine $E_{2}\left(\exp \left(-z_{2} W_{2}\right) \mid q(0+)=q+1\right)$, consider the behaviour of the tagged job with respect to $P_{2}$. If $q(0+)=q+1$ is not less than $m+1$, the tagged job has to wait for $q-m+1$ service completions to start its service because of $m$-LiPS discipline. If $q+1 \leq m$, then the tagged job's service starts at $t=0$. Further, the time interval between its arrival and the first service completion at either node 1 or node 2 is exponentially distributed with parameter $\mu(q+1)$ defined as follows:

$$
\mu(q+1)=\min (N-q-1, s) \mu_{1}+\mu_{2}
$$

Let $X_{q, i}$ be a random variable whose distribution is equal to that of the residual sojourn time experienced by the tagged job under the condition that there exist $q$ jobs at node 2 (including the tagged job), and that the tagged job occupies the $i-t h$ position in the queue. If it is in service, we denote $i=0$. Let $g_{q, i}(z)(z>0)$ be LST of $x_{q, i}$ (the expectation of $\exp \left(-z X_{q, i}\right)$ ). We can easily obtain the followings.

$$
\begin{array}{r}
g_{q, 0}(z)=\frac{1}{z+\mu(q)}\left\{\min (N-q, s) \mu_{1} g_{q+1,0}(z)+\frac{\min (q, m)-1}{\min (q, m)} \mu_{2} g_{q-1,0}(z)\right. \\
\left.+\frac{1}{\min (q, m)} \mu_{2}\right\} \quad(q=1,2, \ldots, N),
\end{array}
$$

$$
\begin{array}{r}
g_{q, i}(z)=\frac{1}{z+\mu(q)}\left\{\min (N-q, s) \mu_{1} g_{q+1, i}(z)+\mu_{2} g_{q-1, i-1}(z)\right\} \\
\quad(q=m+1, \ldots, N ; i=1,2, \ldots, q-m) .
\end{array}
$$

Clearly, we have

$$
E_{2}\left(\exp \left(-z_{2} W_{2}\right) \mid q(0+)=q+1\right)=\dot{g}_{q+1, \max (q+1-m, 0)}\left(z_{2}\right) .
$$


Equations (4.2) are linear equations for $g_{q, i}(z)$ 's. Solving this, we can have an expression of LST transforms for $W_{2}$. It does not have, however, a simple expression even for small $N$ and $m>1$. Differentiating (4.2) or considering $x_{q, i}$ 's directly, we can obtain linear equations giving the first and second moments. Let $x_{q, i}$ and $y_{q, i}$ be $E\left(x_{q, i}\right)$ and $E\left(x_{q, i}{ }^{2}\right)$, respectively, then they satisfy the next equations.

$$
\begin{aligned}
& x_{q, 0}=\frac{1}{\mu(q)}\left\{\min (N-q, s) \mu_{1} x_{q+1,0}+\frac{\min (q, m)-1}{\min (q, m)} \mu_{2} x_{q-1,0}+1\right\} \\
& (q=1,2, \ldots, N) \\
& x_{q, i}=\frac{1}{\mu(q)}\left\{\min (N-q, s) \mu_{1} x_{q+1, i}+\mu_{2} x_{q-1, i-1}+1\right\} \\
& (q=m+1, \ldots, N ; i=1,2, \ldots, q-m) \\
& y_{q, 0}=\frac{2}{\mu(q)^{2}}+\frac{\min (N-q, s) \mu_{1}}{\mu(q)}\left(y_{q+1,0}+\frac{2}{\mu(q)} x_{q+1,0}\right) \\
& +\frac{(\min (q, m)-1) \mu_{2}}{\mu(q) \cdot \min (q, m)}\left(y_{q-1,0}+\frac{2}{\mu(q)} x_{q-1,0}\right) \quad(q=1,2, \ldots, N), \\
& y_{q, i}=\frac{2}{\mu(q)^{2}}+\frac{\min (N-q, s) \mu_{1}}{\mu(q)}\left(y_{q+1, i}+\frac{2}{\mu(q)} x_{q+1, i}\right) \\
& +\frac{\mu_{2}}{\mu(q)}\left(y_{q-1, i-1}+\frac{2}{\mu(q)} x_{q-1, i-1}\right) \\
& (q=m+1, \ldots, N ; \quad i=1,2, \ldots, q-m)
\end{aligned}
$$

Using (4.1), (4.3) and the above equations, we can calculate the correlation coefficients and the coefficients of variation for $w_{1}+w_{2}$. After the calculations for many cases, it can be seen that the coefficient correlations seem to be always nonpositive. For a typical example, the results for the case $N=10$ and $s=2$ is shown in Fig. 2. Since (2.1) and (2.3) do not depend on $m$, the expectation of $W_{2}$ and the distribution of $W_{1}$ also do not depend on $m$. When $\mu_{2} / \mu_{1}$ is small, $W_{1}$ is close to zero and the variance of $W_{1}+W_{2}$ is almost equal to that of $W_{2}$. From Fig. $2(b)$, we see that their variances increase with $m$. The PS discipline gives large variances. 


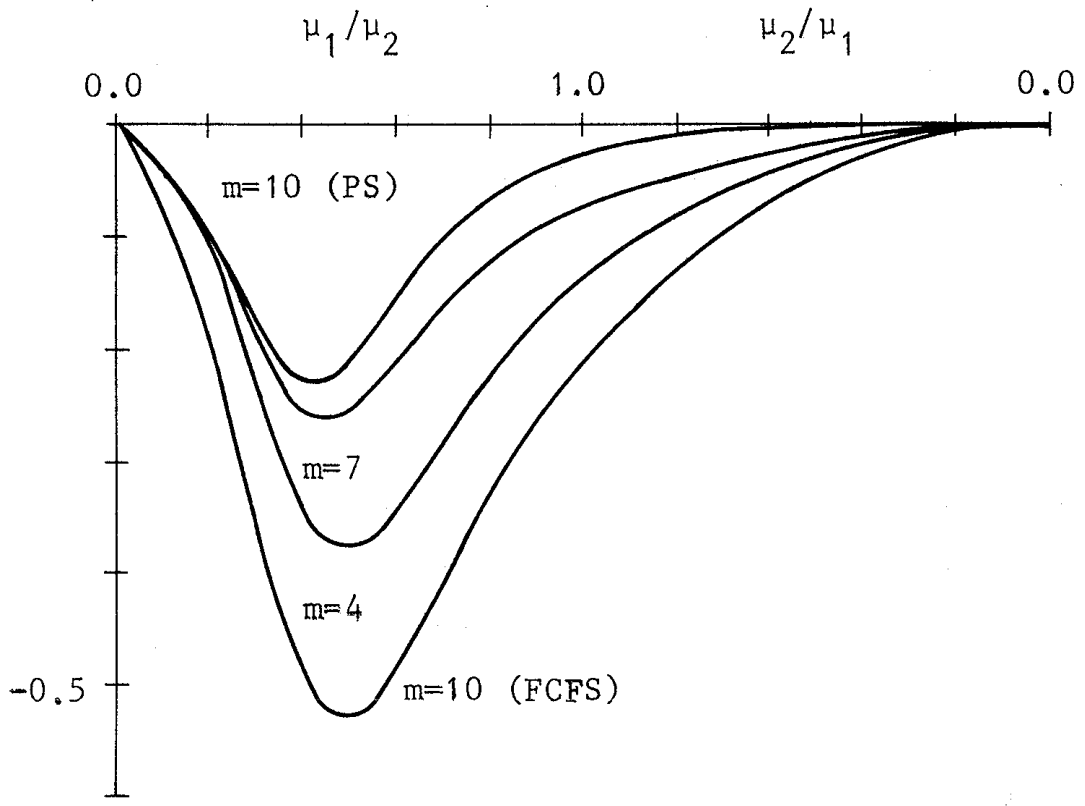

Fig. 2(a) Coefficient Correlation of $W_{1}$ and $W_{2}$ for $N=10, s=2$

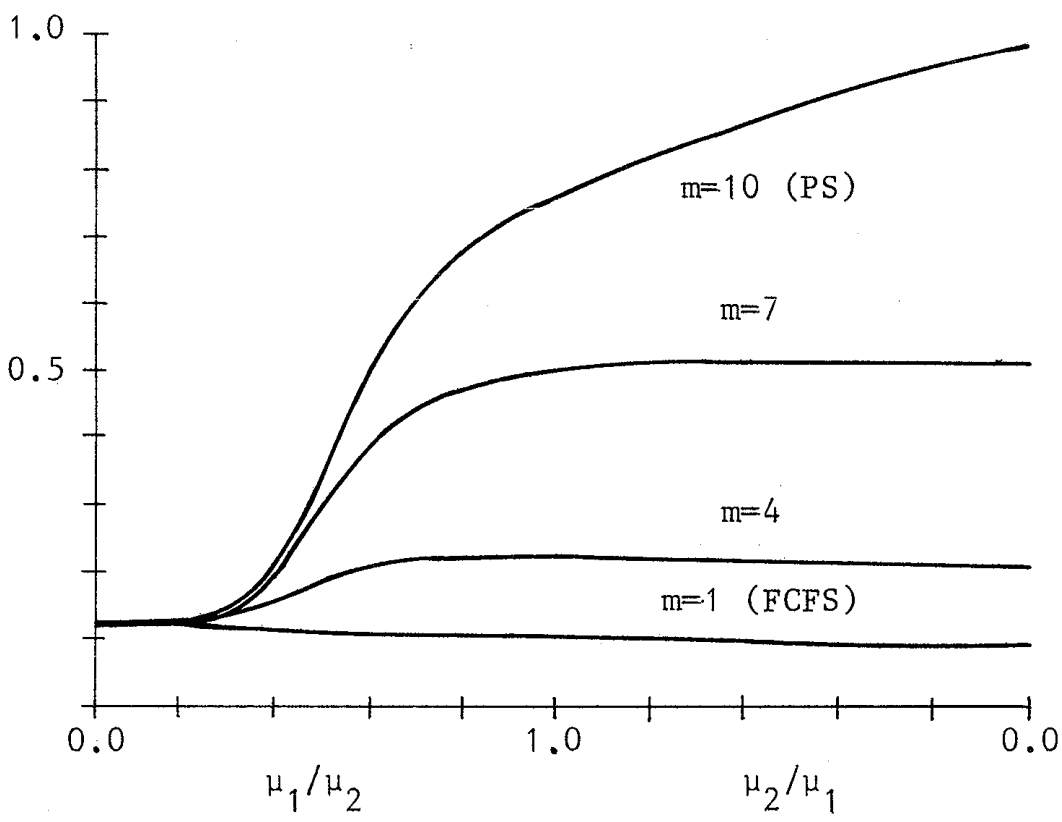

Fig. 2(b) Coefficient of Variation of $w_{1}+W_{2}$ for $N=10, s=2$ 


\section{Concluding Remark}

We derived the linear equations for LST's of the sojourn times and some of their moments. It is also possible to obtain linear differential equations which the conditional distributions of $W_{2}$ satisfy as in Mitra: [12]. From these equations, we can obtain the shape of the sojourn time distributions numerically. However, it requires more complicated computations.

\section{Acknowledgement}

The author would like to thank Professors G. Yamazaki, H. Sakasegawa, M. Miyazawa, and Mr. I. Kino for their valuable discussions and encouragements. He also thanks the referees for their valuable comments.

Appendix 1. Burke 3 proved Lemma 2 for $M / M / s$ system in two different methods. We apply one of his method to our system.

Proof Lemma 2. Since $q_{1}(t)$ is a Markov process, the behaviour of $q_{1}(t) \quad(t>0)$ under the condition $q_{1}(0+)=q+1$ is stochastically identical with respect to $P$ and $P_{1}$. We write this as follows;

$$
\begin{array}{r}
P\left(q_{1}(t)(t>0) \mid q_{1}(0+)=q+1\right)=P_{1}\left(t_{1}(t)(t>0) \mid q_{1}(0+)=q+1\right) \\
\quad(q=0,1, \ldots, N-1) .
\end{array}
$$

Further, we have from Lemma 1

$$
\begin{array}{r}
P\left(q_{1}(\dot{\tau})(t>0) \mid q_{1}(0+)=q+1=P\left(q_{1}(-t)(t>0) \mid q_{1}(0-)=q+1\right)\right. \\
(q=0,1, \ldots, N-1) .
\end{array}
$$

Let $A$ be the event that an arrival occurs at node 2 at $t=0$. From the definition of $P_{2}$, we have

$$
\begin{aligned}
P_{2}\left(q_{1}(-t)(t>0) \mid q_{1}(0-)=q+1\right) \\
\quad=P\left(q_{1}(-t)(t>0), q_{1}(0-)=q+1 \mid A\right) / P\left(q_{1}(0-)=q+1 \mid A\right) \\
\quad=P\left(q_{1}(-t)(t>0) \mid q_{1}(0-)=q+1\right) P\left(q_{1}(0-)=q+1 \mid A\right) / P\left(q_{1}(0-)=q+1 \mid A\right) \\
\quad=P\left(q_{1}(-t)(t>0) \mid q_{1}(0-)=q+1\right),
\end{aligned}
$$

because $q_{1}(-t)$, the time reversed process of $q_{1}(t)$, is also a Markov process 
with respect to $P$. Thus, we have

$$
P_{1}\left(q_{1}(t)(t>0) \mid q_{1}(0+)=q+1\right)=P_{2}\left(q_{1}(-t)(t>0) \mid q_{1}(0-)=q+1\right) .
$$

Under $P_{2}$, the event $\left\{q_{1}(0-)=q+1\right\}$ implies $\left\{q_{1}(0+)=q\right\}$ and vice versa, we obtain the following.

$$
P_{1}\left(q_{1}(t)(t>0) \mid q_{1}(0+)=q+1\right)=P_{2}\left(q_{1}(-t)(t>0) \mid q_{1}(0+)=q\right) \text {. }
$$

Let $\xi(t)(t>0)$ be an arbitrary sample path of $q_{1}(t)$ such that $\xi(0+)=q+1$. We wi11 show the next.

$$
P_{2}\left(W_{1}=x_{i} \mid q_{1}(-t)=\xi(t)(t>0)\right)=P_{1}\left(W_{1}=x_{i} \mid q_{1}(t)=\xi(t)(t>0)\right),
$$

where $\left\{x_{1}, x_{2}, \ldots\right\}$ and $\left\{y_{1}, y_{2}, \ldots\right\}$ be the sequences of downward and upward jump instants of $\xi(t)$, respectively. Let $m_{i}$ be the number of the jobs in service at $x_{i}-0$. Since the discipline at node 1 is FCFS and the service times are exponentially distributed,

$$
P_{1}\left(W_{1}=x_{i} \mid q_{1}(t)=\xi(t)(t>0)\right)
$$

$$
\begin{cases}0, & i \leqq \max (q+1-s, 0) \\ m_{i}^{-1} I_{j=\max }(q+1-s, 0)+1 & i>\max (q+1-s, 0) .\end{cases}
$$

On the other hand, consider the case where $q_{1}(-t)=\xi(t)(t>0)$ with respect to $P_{2}$. In this case $-x_{i}$ 's become arrival instants and $-y_{i}$ 's become service completion instants. Let $-z_{i}$ be the service starting instant of the job arriving at $=x_{i}$ for $i>\max (q+1=s, 0)$. Then, we have

$$
-z_{i}= \begin{cases}-x_{i} & \text { if } q_{1}\left(-x_{i}+0\right) \leqq s, \\ -y_{j(i)} & \text { if } q_{1}\left(-x_{i}+0\right) \geqq s+1,\end{cases}
$$

where $-y_{j}(i)$ is the $g_{1}\left(-x_{i}+0\right)-s$ th point of $-y_{j}$ 's after $-x_{i}$. If $z_{i} \neq x_{i}$, then the numbers of the jobs at $-x_{i}+0$ and at $-z_{i}-0$ are greater than $s$, that is, the numbers of the jobs in service at $-x_{i}+0$ and at $-z_{i}+0$ are both $s$. Thus the number of the jobs in service at $-z_{i}+0$ is $m_{i}$ for all $i$. Now, the joint distribution of elapsed service times of the jobs in service at arbitrary time $t$ are symmetric given $q_{1}(u)(u>t)$ (see Appendix 2). So, the probability that the tagged job's service start at $-z_{i}$ under the condition that it is in service at $-z_{i}+0$ is $1 / m_{i}$. The event $\left\{w_{1}=x_{i}\right\}$ implies the tagged job's service starts at $\left.-z_{i}\right\}$ and vice versa. Thus, the left hand side of (A.5) is equal to the right hand side of (A.6). We obtain (A.5). Integrating this by the probability density (A.4), we obtain Lemma 2 . 
Appendix 2. Consider $G / M / s$ with FCFS discipline, where $G$ is not necessary GI. Suppose that there are $m$ jobs in service at an arbitrary time $t$. We label the numbers $1,2, \ldots, m$ to the $m$ jobs at random. Let $X_{i}, Y_{i}$ be the elapsed and residual service times of the $i-t h$ job, respectively. Then, it holds that

$$
P\left(x_{1} \leqq x_{1}, x_{2} \leqq x_{2}, \ldots, x_{m} \leqq x_{m} \mid y_{1}=y_{1}, y_{2}=y_{2}, \ldots, y_{m}=y_{m}\right)
$$

is symmetric for $x_{1}, x_{2}, \ldots, x_{m}$, and does not depend on $y_{1}, y_{2}, \ldots, y_{m}$, where $P$ is an arbitrary probability measure which is wel1 defined for our system.

Proof: Since service times are exponentially distributed and our 1abe1ing does not depend on the others, we have

$$
\begin{aligned}
& P\left(y_{1} \leqq y_{1}, \ldots, y_{m} \leqq y_{m} \mid x_{1}, \ldots, x_{m}\right)=P\left(y_{1} \leqq y_{1}\right), \ldots P\left(y_{m} \leqq y_{m}\right), \\
& P\left(x_{1} \leqq x_{1}, \ldots, x_{m} \leqq x_{m}\right) \text { is symmetric for } x_{1}, \ldots, x_{m} .
\end{aligned}
$$

Then we have

$$
\begin{aligned}
P\left(\left(X_{1}, \ldots, X_{m}\right) \varepsilon A, \quad\left(Y_{1}, \ldots, Y_{m}\right) \varepsilon B\right) \\
\quad=\int_{A} P\left(\left(Y_{1}, \ldots, Y_{m}\right) \varepsilon B \mid X_{1}, \ldots, X_{m}\right) d P\left(X_{1}, \ldots, x_{m}\right) \\
=P\left(\left(Y_{1}, \ldots, Y_{m}\right) \varepsilon B\right) \int_{A} d P\left(X_{1}, \ldots, X_{m}\right) \\
=P\left(\left(Y_{1}, \ldots, Y_{m}\right) \varepsilon B\right) P\left(\left(X_{1}, \ldots, X_{m}\right) \varepsilon A\right),
\end{aligned}
$$

where $A$ and $B$ are arbitrary m-dimensional Borel sets. Thus, the random vector $\left(x_{1}, \ldots, x_{m}\right)$ is independent of $Y_{1}, \ldots, Y_{m}$, and $Y_{i}$ 's are independent each other. Q.E.D.

The result in Appendix 2 means that the behaviour of these $m$ jobs at the past are stochastically uniform and independent of the future. The next follows, which is used in the proof of Lemma 2.

$$
P\left(X_{1}=0 \mid \text { only one of } X_{i} \text { s is } 0, Y_{1}=y_{1}, Y_{2}=y_{2}, \ldots, Y_{m}=y_{m}\right)=1 / m
$$

\section{References}

[1] Boxma, O.J., Donk, P. (1982): On Response-time and Cycle Time Distribution in cyclic queues, Perf. Eval., Vo1.2, 181-194.

[2] Boxma, O.J., F.P. Ke11y, A.G. Konheim (1984): The Product Form Distribution in Cyclic Exponential Queues, J. ACM., 31, 128-133. 
[3] Burke, P.J. (1968): The Output Process of a Stationary M/M/s Queueing System, A.M.S., 39, 1144-1152.

[4] Chow, W.M. (1980): The Cycletime Distribution of Exponential Queues, J. $A C M ., 27,281=286$.

[5] Coffman, E.G., R.R. Muntz, H. Trotter (1970): Waiting Time Distributions for Processor-sharing Systems, J. ACM., 17, 123-130.

[6] Franken, P., D. König, U. Arndt, V. Schmitdt: Queues and Point Processes, J. Wiley, Chichester 1982 .

[7] Ishiguro, M. (1980): Running Time Delays in Processor-sharing System, J. Inf. Processing, 3, 38-44.

[8] Kawashima, T. (1978): Turnaround time equations in queueing networks, J. Opn. Res. Soc. Japan, 21, 477-485.

[9] Kawashima, T. (1982): A property of Two Palm Measures in Queueing Networks and its Applications, J. Opn. Res. Soc. Japan., 25, 16-28.

[10] Kawashima, T., N. Torigoe (1983): The Cycle Time Distribution in a Central Server Queueing System with Multi-server Stations, Memo. Def. Acad., 23, 155-160.

[11] Lavenberg, S.S., M. Reiser (1980): Stationary State Probabilities at Arrival Instants for Closed Queueing Networks with Multiple Types of Nodes, J. Appl. Prob., 17, 1048-1061.

[12] Mitra, D. (1981): Waiting time Distributions from Closed Queueing Network Models of Shared-processor Systems, Performance 81, 113-131, North-Holland, Amsterdam.

[13] Reich, E. (1959): Waiting Times when Queues are in Tandem, A.M.S., 28, 76-773.

[14] Schassberger, R., H. Daduna (1983): The Time for a Round Trip in a Cycle of Exponential queues, J. ACM., 30, 146-150.

[15] Schassberger, R., H. Daduna (1984): Sojourn Times in Queveing Network with Multiserver Nodes, Preprint.

[16] Yamazaki, G., H. Sakasegawa (1984): Limited Processor Sharing Queues (in Japanese), Kokyuroku 519, 99-113. Institute of Math, Kyoto Univ., Kyoto.

Takeshi KAWASHIMA: Defence Academy, Hashirimizu, $1-10-20$

Yokosuka, 239, Japan 


\section{$m$-LiPS規律を含む循環型待ち行列網の滞在時間について}

防衛大学校川 島武

空口 $1 ， 2$ からなる循環待ち行列網において，空口 1 の規律はFCFSであり，空口 2 の規律は $m$ 一 Li PSであるモデルを考察する。 $m$ - LiPS とはサービス率が列の長さに依存する規律の一種で，最 大 $m$ 個のジョブに対して迄そのサービス能力を等配分してサービスする規律である。M個のイニシエー ターを持つ計算機システムのモデルになっている。 $m=1$ ならばFCFSと一致し， $m$ が網内のジョ ブ数以上ならばPSと同じになる。要求サービス時間は何れの空口においてす，指数分布に従うあの とする。

ここでは一個のジョブの空口 $1 ， 2$ での滞在時間の同時分布を考察する。乙れには網の時間経過に 依る変化を考慮しなくてはならず，平衡確率分布だけでは充分ではない。待ち行列過程が時間的に可 逆なマルコフ過程になることから悹口10退去時点での網の状態と滞在時間の同時分布を導き，乙れか らラプラス変換と $1 ， 2$ 次のモーメントを与える連立方程式を導く。てれにより，いくつかの場合につ いて相関係数と和の変動係数を求めている。 